\title{
Targeting hepatic glucokinase to treat diabetes with TTP399, a hepatoselective glucokinase activator
}

\author{
Adrian Vella ${ }^{1}$, Jennifer L. R. Freeman ${ }^{2}$, Imogene Dunn $^{2}$, Kit Keller $^{2}$, \\ John B. Buse ${ }^{3}$, Carmen Valcarce ${ }^{2 *}$
}

\begin{abstract}
The therapeutic success of interventions targeting glucokinase (GK) activation for the treatment of type 2 diabetes has been limited by hypoglycemia, steatohepatitis, and loss of efficacy over time. The clinical characteristics of patients with GK-activating mutations or GK regulatory protein (GKRP) loss-of-function mutations suggest that a hepatoselective GK activator (GKA) that does not activate GK in $\beta$ cells or affect the GK-GKRP interaction may reduce hyperglycemia in patients with type 2 diabetes while limiting hypoglycemia and liver-associated adverse effects. Here, we review the rationale for TTP399, an oral hepatoselective GKA, and its progression from preclinical to clinical development, with an emphasis on the results of a randomized, double-blind, placebo- and activecontrolled phase 2 study of TTP399 in patients with type 2 diabetes. In this 6-month study, TTP399 (800 mg/day) was associated with a clinically significant and sustained reduction in glycated hemoglobin, with a placebosubtracted least squares mean $\mathrm{HbA}_{1 \mathrm{c}}$ change from baseline of $-0.9 \%(P<0.01)$. Compared to placebo, TTP399 ( $800 \mathrm{mg} /$ day) also increased high-density lipoprotein cholesterol $(3.2 \mathrm{mg} / \mathrm{dl} ; P<0.05)$, decreased fasting plasma glucagon $(-20 \mathrm{pg} / \mathrm{ml} ; P<0.05)$, and decreased weight in patients weighing $\geq 100 \mathrm{~kg}(-3.4 \mathrm{~kg} ; P<0.05)$. TTP399 did not cause hypoglycemia, had no detrimental effect on plasma lipids or liver enzymes, and did not increase blood pressure, highlighting the importance of tissue selectivity and preservation of physiological regulation when targeting key metabolic regulators such as GK.
\end{abstract}

\section{INTRODUCTION}

The past decade has witnessed a proliferation of new therapies for type 2 diabetes, driven in part by a greater understanding of the pathophysiology of the disease. Identification of pathways predisposing to the disease has helped to focus development of compounds that target these processes (1).

Glucokinase (GK) - the enzyme catalyzing glucose phosphorylation, the rate-limiting step in glycolysis, and a major controller of glycogen synthesis $(2,3)$-is one such target. Heterozygous inactivating mutations of this enzyme produce an altered set point, increasing the threshold for insulin secretion (4), whereas homozygous inactivating mutations produce a more severe phenotype that presents at birth as permanent neonatal diabetes mellitus (5). Conversely, activating mutations of this gene cause neonatal hyperinsulinemic hypoglycemia $(5,6)$. GK acts as a glucose sensor in a variety of tissues-a role driven by the kinetics of glucose binding and the lack of inhibition of GK by the end product of the reaction it catalyzes $(7,8)$.

In the $\beta$ cell, GK establishes the threshold for glucose-stimulated insulin secretion (7), whereas in hepatocytes, it regulates glucose uptake and glycogen synthesis (5). The reduction in hepatic glucose uptake and glycogen synthesis observed in people with type 2 diabetes is attributable, at least in part, to reduced hepatic GK activity (9). Selective activation of hepatic GK in transgenic animals produces glucose lowering without attendant hypoglycemia (10). Glucose uptake and phosphorylation also drive glycogen synthesis and play a critical role in lipogenesis (5). In the hepatocyte, GK is regulated

\footnotetext{
${ }^{1}$ Division of Endocrinology and Diabetes, Department of Medicine, Mayo Clinic Rochester, MN 55905, USA. 2 vTv Therapeutics Inc. and vTV Therapeutics LLC, High Point, NC 27265, USA. ${ }^{3}$ Division of Endocrinology and Metabolism, Department of Medicine, University of North Carolina School of Medicine, Chapel Hill, NC 27599, USA.

*Corresponding author. Email: cvalcarce@vtvtherapeutics.com
}

by the GK regulatory protein (GKRP) that sequesters the enzyme in an inactive conformation in the presence of low glucose concentrations (11-13). Numerous reports of mutations affecting GKRP expression, localization, and activity indicate that these mutations affect not only glucose homeostasis but also triglyceride (TG) metabolism (14-19).

Although multiple small-molecule activators of GK have been in clinical development, their initial therapeutic promise has been hampered by the occurrence of hypoglycemia, increased TG concentrations, and loss of efficacy over time (20-24). These adverse events (AEs) were related to ongoing $\beta$ cell activation (as predicted by the phenotype of patients with GK-activating mutations) and may be related to the development of hepatic steatosis (consistent with the disruption of GK and GKRP interaction by these activators and evidence from preclinical trials) $(23,25,26)$.

The clinical characteristics of patients with GK-activating mutations or GKRP loss-of-function mutations suggest that hepatoselective GK activators (GKAs) that neither activate GK in $\beta$ cells nor affect the GK-GKRP interaction would be less likely to cause these AEs. Accordingly, we developed TTP399, a hepatoselective agent that improves glycemic control in both animal models of type 2 diabetes and patients with type 2 diabetes by activating GK. TTP399 improved glycemic control and did not induce hypoglycemia, dyslipidemia, or pathological increases of glycogen and TG in the liver. The presence of TTP399 did not appear to disrupt the interaction between GK and GKRP in the presence of normoglycemia, perhaps explaining the absence of dyslipidemia and altered liver function tests in humans. Animal models exhibited decreased hepatic fat in response to TTP399 administration. Here, we describe the key studies in the TTP399 preclinical and clinical development program, including the design and results of the AGATA (Add Glucokinase Activator to Target A1c) trial, a phase $2 \mathrm{~b}$ trial of TTP399 in patients with type 2 diabetes, and its impact on the physiological regulation of glucose metabolism. 


\section{RESULTS}

\section{Design and discovery of TTP399}

The goal of the discovery phase of this project was to identify and characterize small-molecule compounds with the ability to increase GK activity in the liver without affecting the physiological role of GK (active when plasma glucose concentrations are high and inactive at low/normal plasma glucose concentration). Compounds were initially screened for efficacy and potency on purified human and rat $\mathrm{GK}$ in the presence of hyperglycemia (15 mM glucose) or normoglycemia ( $5 \mathrm{mM}$ glucose) and then tested for their ability to increase glycogen and lactate production in rat and human hepatocytes incubated in the presence of $15 \mathrm{mM}$ glucose. Active compounds were further tested for their ability to induce insulin secretion in pancreatic $\beta$ cells/mouse islets in the presence of hypoglycemia ( $3 \mathrm{mM}$ glucose) and hyperglycemia (15 $\mathrm{mM}$ glucose). The compounds that did not stimulate insulin secretion were further characterized to confirm liver selectivity. The liver selectivity of TTP399 was assessed by direct and indirect techniques, which demonstrated that TTP399 is a functional hepatoselective GKA.

\section{In vitro characterization of TTP399 and its effects on glucose metabolism}

The median effective concentration $\left(\mathrm{EC}_{50}\right)$ of TTP399 for human $\mathrm{GK}$ at high glucose concentration $(15 \mathrm{mM})$ was $304 \mathrm{nM}$, and that at normoglycemia (5 mM) was $762 \mathrm{nM}$ (fig. S1). TTP399 increased glucose metabolism in rat hepatocytes, measured as an increase in glycogen content or lactate production (fig. S2). The $\mathrm{EC}_{50}$ values were 2.39 and $2.64 \mu \mathrm{M}$ in the presence of $15 \mathrm{mM}$ glucose for lactate production and glycogen content, respectively.

Time-, temperature-, and concentration-dependent uptake studies revealed active carrier-mediated transport of TTP399 into rat, canine, and human hepatocytes but not into rat $\beta$ cells. Figure S3 illustrates the selective uptake of TTP399 into rat hepatocytes compared with rat $\beta$ cells. The hepatocyte concentration of TTP399 was $>10$ times of that observed in rat $\beta$ cells at all concentrations tested.

The results from the mouse islet and rat $\beta$ cell studies demonstrate that TTP399 had minor effects on insulin secretion, with an $\mathrm{EC}_{50}$ of $>10 \mu \mathrm{M}$ at basal glucose concentrations. For example, in perfused mouse islets, the magnitude of the response to $10 \mu \mathrm{M}$ TTP399 was $20 \%$ of that seen with $15 \mathrm{mM}$ glucose (Fig. 1).

At concentrations near or slightly above the $\mathrm{EC}_{50}(1$ and $3 \mu \mathrm{M})$, TTP399 did not affect the physiologic translocation of GK into and out of the nucleus in response to changes in glucose concentration (Fig. 2). Under normoglycemic conditions (5 mM glucose), GK was predominantly located in the nucleus, both in the presence and absence of TTP399 (Fig. 2B), indicating that GKRP can bind, inactivate, and sequester GK, even in the presence of GKA. During hyperglycemic conditions ( 15 and $25 \mathrm{mM}$ glucose), nuclear intensity was reduced, implying that GK had translocated out of the nucleus. This was unaffected by the presence of TTP399. These results support the hypothesis that, at the concentrations used in this study, the physiological regulation of GK by GKRP in the liver is maintained in the presence of TTP399.

\section{In vivo characterization of TTP399}

Treatment of nondiabetic fasted rats with TTP399 [200 mg/kg, per os (p.o.)] resulted in changes in plasma glucose concentrations that were indistinguishable from those observed in rats treated with vehicle (Fig. 3A). Similarly, no change in plasma insulin concentrations was seen after dosing with TTP399 or vehicle (Fig. 3B). In contrast, the nonliver-selective GK agonist NNC80-0000-3281 (200 mg/kg, p.o.)

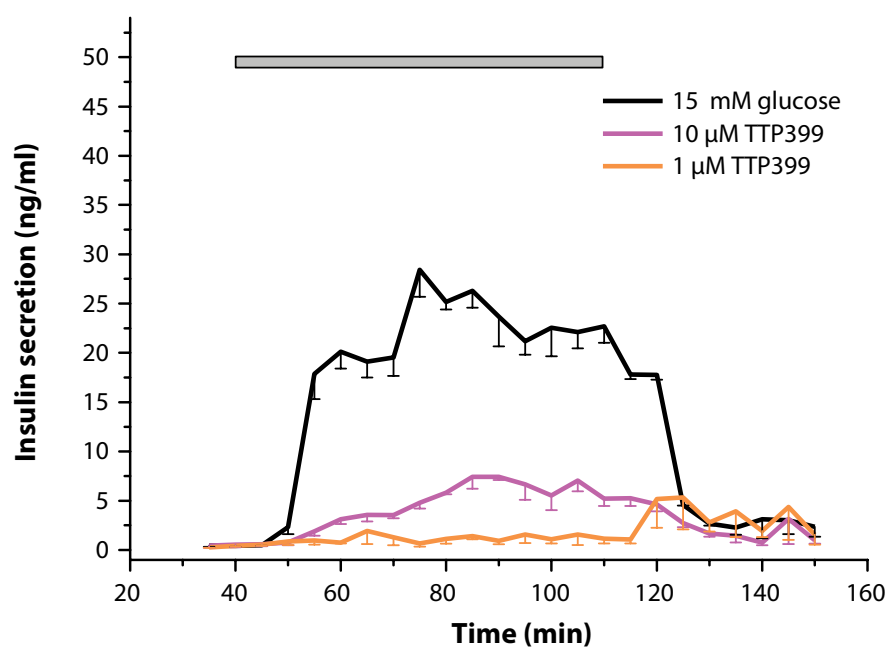

Fig. 1. Insulin secretory response to glucose and TTP399 in perfused mouse islets. TTP399 was tested in the presence of $3 \mathrm{mM}$ glucose. The horizontal gray bar indicates when islets were exposed to experimental treatments. Data are means \pm $\operatorname{SEM}(n=6)$.

caused large increases in plasma insulin and subsequent reductions in plasma glucose concentration (Fig. 3).

Preclinical proof of concept $(\mathrm{PoC})$ was defined by the capacity of the compound to lower glycated hemoglobin $\left(\mathrm{HbA}_{1 \mathrm{c}}\right)$ after chronic administration. The ob/ob mouse model of severe diabetes and dyslipidemia, characterized by hyperinsulinemia, obesity, insulin resistance, and elevated hepatic glucose production, was one of the models used for this purpose. Four weeks of treatment of diabetic Umeå ob/ob mice with TTP399 (75 or $150 \mathrm{mg} / \mathrm{kg}$ per day) resulted in improved glucose homeostasis, manifested by a significant reduction in $\mathrm{HbA}_{1 \mathrm{c}}$ $\left[\mathrm{HbA}_{1 \mathrm{c}}\right.$ change from baseline at week 4: vehicle, $0.49 \pm 0.27 \%$; TTP399 $(75 \mathrm{mg} / \mathrm{kg}),-0.76 \pm 0.14 \%(P<0.01)$; TTP399 $(150 \mathrm{mg} / \mathrm{kg}),-1.23 \pm$ $0.28 \%(P<0.001)$; fig. S4] and lower blood glucose concentrations during a 30-hour profile (table S1). Plasma insulin concentrations were not different from those observed in the vehicle-treated mice (table S2). Treatment with TTP399 decreased lactate concentrations and liver glycogen depots, which are increased in this animal model. The lipid profile also improved with treatment, with reduced plasma and liver TG concentrations (fig. S5). TTP399 treatment also resulted in reduced weight gain at the highest dose tested [0.5 g with TTP399 $(150 \mathrm{mg} / \mathrm{kg}$ per day) at 4 weeks versus $3 \mathrm{~g}$ with placebo; $P<0.01$; fig. $\mathrm{S} 6 \mathrm{~A}]$. Cumulative food intake in the three groups was similar over the 4-week study (fig. S6B).

To confirm the results observed in ob/ob mice in a nonrodent model, we tested TTP399 in Gottingen minipigs. TTP399 was effective in reducing plasma glucose during an oral glucose tolerance test (OGTT) in this model. Moreover, there were no significant changes in mean plasma TG concentrations, lactic acid concentrations, hepaticfree glycerol, TG, or glycogen content in minipigs treated with TTP399 (50 mg/kg per day) for 13 weeks compared with animals treated with vehicle (tables S3 and S4).

Minipigs treated with $500 \mathrm{mg}$ of metformin twice daily demonstrated a slight increase in blood glucose after ingestion of a meal supplemented with glucose $(1 \mathrm{~g} / \mathrm{kg})$ (fig. S7). When minipigs were pretreated with TTP399 $(50 \mathrm{mg} / \mathrm{kg})$ in addition to metformin before the food and glucose challenge, the blood glucose excursion was eliminated $(P<0.05,2$ hours after ingestion; fig. S7). No differences 


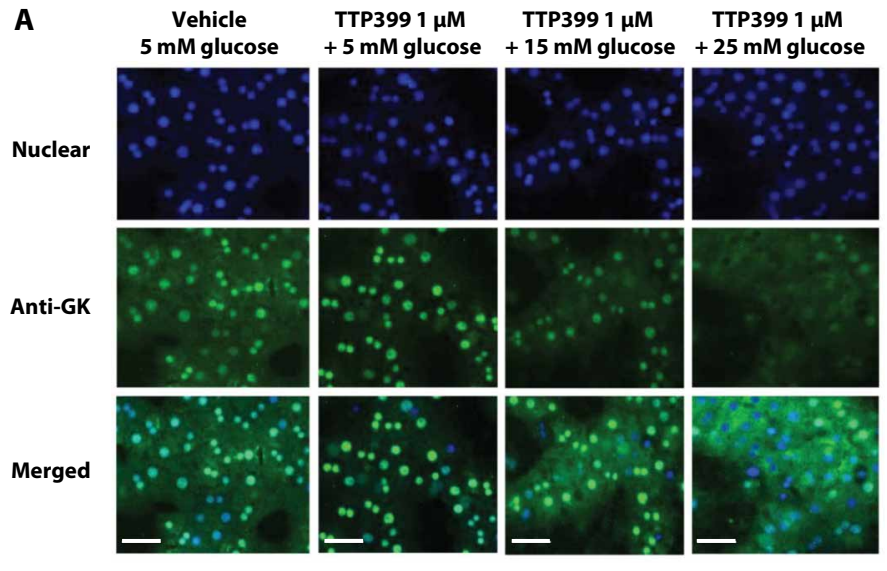

B

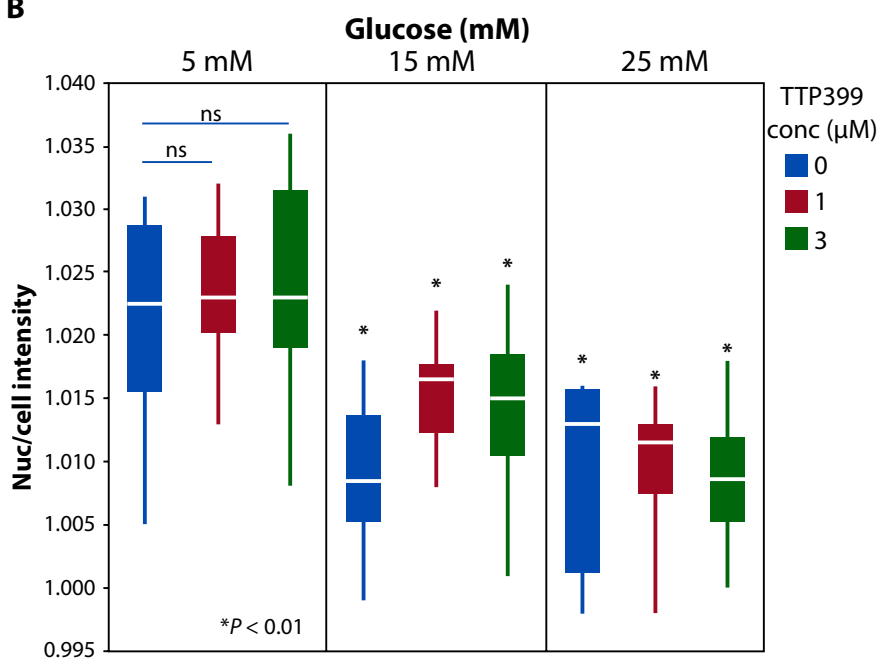

Fig. 2. GK nuclear translocation. (A) GK translocation at $5 \mathrm{mM}$ glucose in the presence or absence of TTP399 (green, GK; blue, Hoechst nuclear stain). Scale bars, $50 \mu \mathrm{m}$. (B) Changes in nuclear/cell intensity ratio of GK staining in the presence of 5, 15, and $25 \mathrm{mM}$ glucose. ns, not significant. Data are presented as median (midline), 25 th and 75 th quartiles (box), and $1.5 \times$ interquartile range (upper and lower whiskers) of observations of 250 to 300 nuclei per well $(n=8)$.

in insulin secretion were observed between the minipigs treated with metformin alone and with combination therapy (fig. S7).

\section{Initial clinical experience with TTP399}

TTP399 has been evaluated in 10 clinical trials (phase 1, phase $1 \mathrm{~b}$, and phase 2a). In clinical studies of patients with type 2 diabetes, TTP399 reduced postprandial glucose and increased the percentage of time glycemic values were in the normal range $(27,28)$. Incidence of AEs with TTP399 was similar to that observed with placebo, with none that had an obvious relationship to dose.

\section{Clinical PoC: efficacy and safety in a phase $\mathbf{2 b}$ clinical trial Study design}

The AGATA trial was a phase $2 \mathrm{~b}$, randomized, double-blind, placeboand active-controlled, parallel group study in patients with type 2 diabetes receiving a stable dose of metformin. Participants were randomized to one of four treatment regimens for a 6-month treatment period: (i) TTP399 (400 mg) once daily; (ii) TTP399 (800 mg)

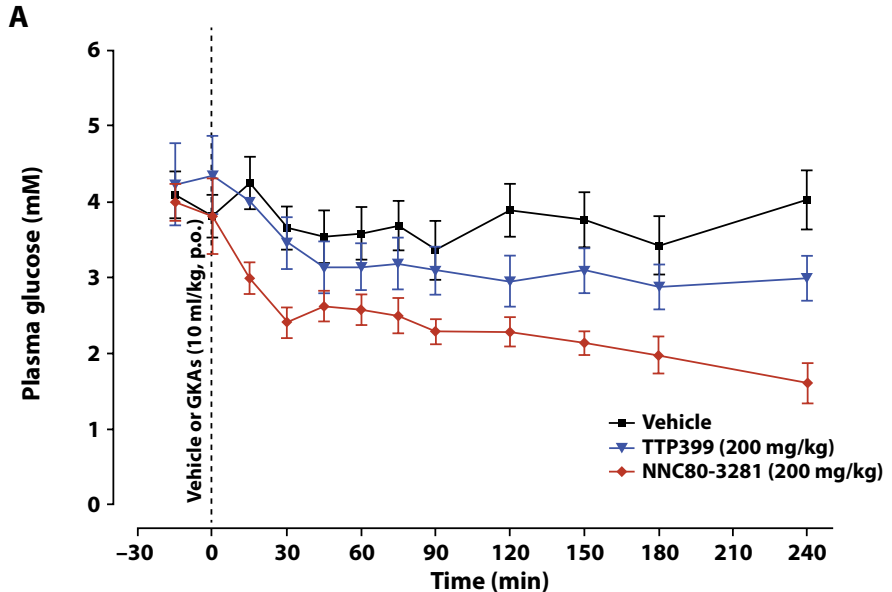

B

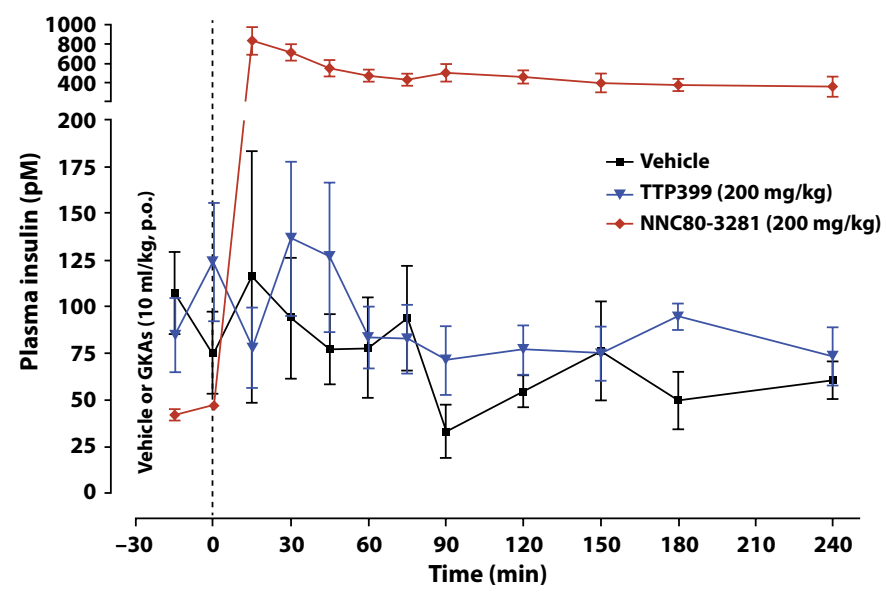

Fig. 3. Effect of TTP399 and NNC80-3281 on plasma glucose and insulin in fasted rats. (A) Plasma glucose and (B) plasma insulin concentrations in rats. Data are means $\pm \operatorname{SEM}$ ( $n=7$ per group).

once daily; (iii) the DPP-4 inhibitor sitagliptin (100 mg) once daily; or (iv) placebo once daily.

The primary endpoint was change from baseline in $\mathrm{HbA}_{1 \mathrm{c}}$ at 6 months. Secondary endpoints included changes in body weight, lipids [low-density lipoprotein cholesterol (LDL-C), high-density lipoprotein cholesterol (HDL-C), TGs, and total cholesterol], insulin, lactate, C-peptide, glucagon, and glucagon-like peptide-1 (GLP-1). Safety was assessed by AEs, laboratory tests, vital signs, and electrocardiograms.

\section{Patients}

A total of 190 patients were randomized between 1 April 2015 and 5 February 2016 (Fig. 4), of whom 124 completed the dosing period and 115 completed the follow-up visit. The discontinuation rate did not differ between groups. Baseline characteristics and demographics were generally comparable among the four treatment groups (Table 1).

\section{Primary outcome}

Placebo-subtracted changes in $\mathrm{HbA}_{1 \mathrm{c}}$ levels at month 6 were $-0.9 \%$ for TTP399 (800 mg) [95\% confidence interval (CI), -1.5 to $-0.3 ; P<$ 0.01 ], $-0.2 \%$ for TTP399 ( $400 \mathrm{mg}$ ) ( $95 \% \mathrm{CI},-0.8$ to 0.5 ), and $-1.0 \%$ with sitagliptin (95\% CI, -1.5 to -0.5 ) (Table 2). Reduction in $\mathrm{HbA}_{1 \mathrm{c}}$ 


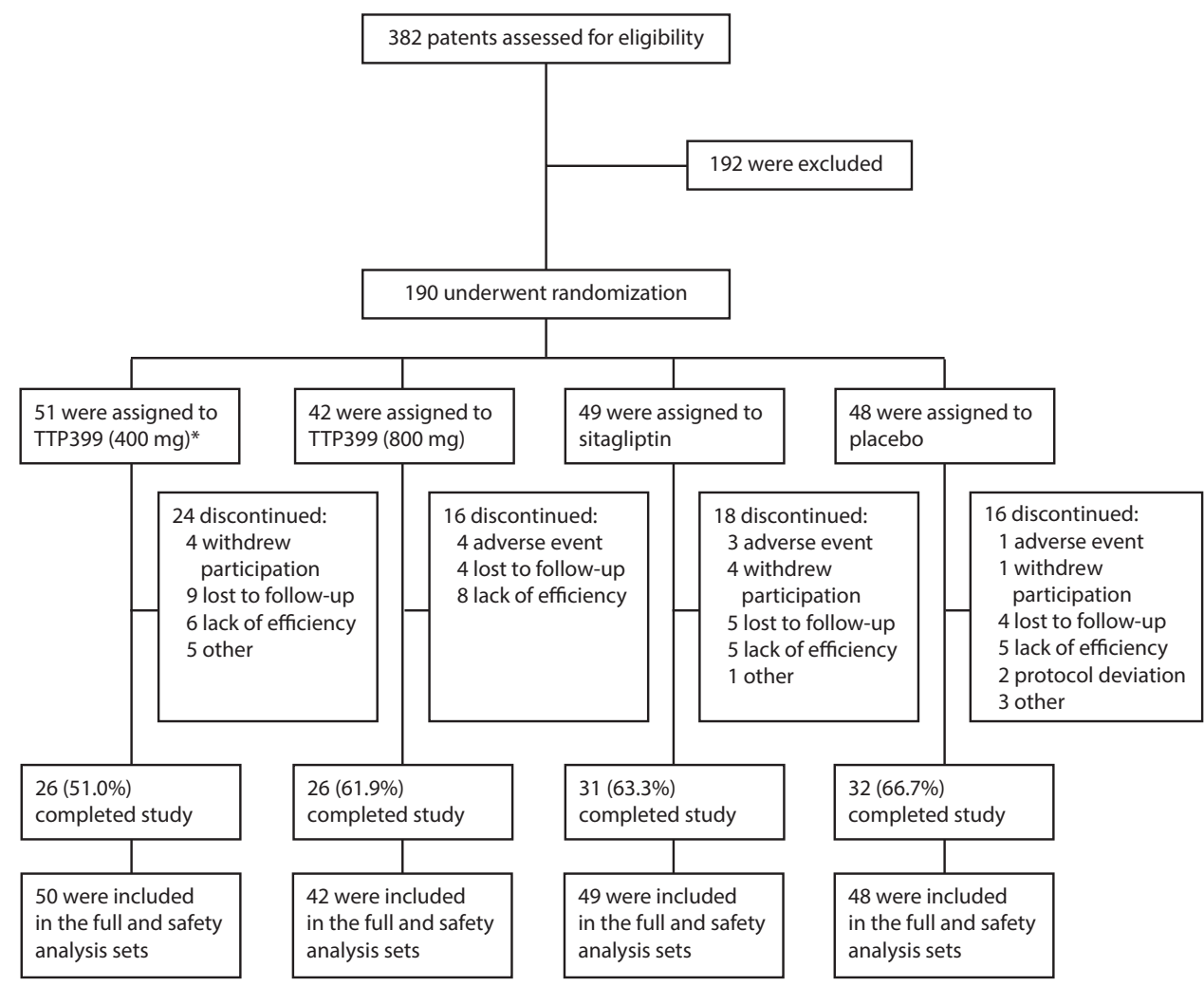

*1 patient was randomized to TTP399 $(400 \mathrm{mg})$ but did not receive treatment.

Fig. 4. Patient disposition.

with TTP399 (800 mg) was first observed at month 3 and was sustained over the 6 months of treatment (Fig. 5A). Results of a supportive analysis, including a last-observation-carried-forward (LOCF) analysis for handling missing data and a complete-cases analysis (Fig. 5B), confirmed the conclusion of the primary intent-to-treat (ITT) analysis.

\section{Secondary outcomes}

TTP399 administration did not significantly decrease weight with TTP399 (800 or $400 \mathrm{mg} /$ day) (Fig. 5C and Table 2). In patients with entry body weight of $\geq 100 \mathrm{~kg}$, reductions in body weight were significantly greater than placebo with TTP399 (800 mg/day) $[-3.4 \mathrm{~kg}$; 95\% CI, -6.2 to $-0.6(P<0.05)$ ] but not with TTP399 (400 mg/day) $(-0.2 \mathrm{~kg} ; 95 \% \mathrm{CI},-2.7$ to 2.4$)$ or sitagliptin ( $-0.6 \mathrm{~kg}$; $95 \% \mathrm{CI},-3.1$ to 2.0$)$.

TTP399 (800 mg/day), but not sitagliptin or TTP399 (400 mg/day), significantly decreased fasting glucagon concentrations by $19.6 \mathrm{pg} / \mathrm{ml}$ (95\% CI, -34.8 to $-4.4 ; P<0.05$ versus placebo). TTP399 did not change fasting active GLP-1, lactate, insulin, and C-peptide concentrations (Table 2 and fig. S8).

Treatment with TTP399 (800 mg/day) significantly increased HDL-C versus placebo $[+3.2 \mathrm{mg} / \mathrm{dl}$; $95 \% \mathrm{CI}, 0.2$ to $6.1(P<0.05)]$, as shown in Table 2. Changes in HDL-C with TTP399 (400 mg/day) or sitagliptin were not statistically significant. No statistically significant changes in TGs, LDL-C, non-HDL-C, or total cholesterol were observed.

\section{Safety}

The percentages of individuals reporting treatment-emergent AEs (TEAEs) were generally similar among groups (Table 3 ), with no serious AEs reported. Study discontinuations due to treatment-related
TEAEs occurred in four patients $(9.5 \%)$ in the TTP399 group ( $800 \mathrm{mg} /$ day $)$, three patients $(6.1 \%)$ in the sitagliptin group, and one patient $(2.1 \%)$ in the placebo group. The most commonly reported TEAEs, occurring in at least $5 \%$ of patients, were headache, upper respiratory tract infection, urinary tract infection, diarrhea, nausea, hypoglycemia, cough, and nasopharyngitis.

One case of documented symptomatic hypoglycemia was reported in each of the groups assigned to TTP399 (800 mg), sitagliptin, or placebo. No cases of severe hypoglycemia or confirmed asymptomatic hypoglycemia were reported.

Assessments of other laboratory findings and vital signs were generally unremarkable. There were no AE reports of increases in alanine aminotransferase (ALT), bilirubin, or alkaline phosphatase in any treatment group. An asymptomatic increase in aspartate aminotransferase (AST) concentration at follow-up (2 weeks after discontinuation of the drug) in one patient in the TTP399 group (400 mg/day) was noted; however, this AST elevation was not deemed to be treatment-related by the investigator. Increased blood pressure was reported as an $\mathrm{AE}$ in one patient in the sitagliptin group. Hypertension was reported as an $\mathrm{AE}$ in one patient on placebo and one patient on TTP399 (400 mg). No AEs related to blood pressure were reported among patients assigned to TTP399 (800 mg).

\section{DISCUSSION}

Because of the critical importance of GK to glucose homeostasis and its potential as a therapeutic target for type 2 diabetes, numerous GKAs have been developed, evaluated, and unfortunately, discontinued $(23,25)$. Published preclinical data are now available on at least 30 GKAs, including those with activity in both liver and pancreas, partial GKA activators, and hepatoselective activators. The data presented here indicate that TTP399 is hepatoselective and substantially improves glycemic control in people with type 2 diabetes without causing hypoglycemia or hyperlipidemia.

Improvements in fasting glucose and postprandial glucose have been demonstrated in a variety of diabetic animal models, including diet-induced models, using members of this therapeutic class (29-32). However, most have shown a potential to cause hypoglycemia, dyslipidemia, and/or fatty liver, as well as hypoglycemia-related pathology such as vasculopathy and neuropathy $(30,33-36)$.

The earliest compounds in this class were dual hepatic and pancreatic activators that caused hypoglycemia, resulting in a shift in focus toward either "partial activators" [which avoid reducing the $K_{\mathrm{m}}$ (Michaelis constant) for glucose to inappropriately low levels] or hepatoselective compounds $(33,37,38)$. Although such compounds reduced the risk for hypoglycemia, many were associated with dyslipidemia and fatty liver in preclinical studies $(20-23,25)$. Clinical results to date for many of 
Table 1. Patient demographics and baseline characteristics. FPG, fasting plasma glucose.

\begin{tabular}{|c|c|c|c|c|}
\hline Characteristic & TTP399 $(400 \mathrm{mg})(n=50)$ & $\begin{array}{c}\text { TTP399 (800 mg) } \\
(n=42)\end{array}$ & $\begin{array}{l}\text { Sitagliptin } \\
(n=49)\end{array}$ & $\begin{array}{l}\text { Placebo } \\
(n=48)\end{array}$ \\
\hline Mean age, $y( \pm S D)$ & $52.8 \pm 10.7$ & $57.0 \pm 8.5$ & $55.1 \pm 9.6$ & $55.7 \pm 11.7$ \\
\hline Male, $n(\%)$ & $23(46.0)$ & $22(52.4)$ & $29(59.2)$ & $27(56.3)$ \\
\hline White, $n(\%)$ & $42(84.0)$ & $32(76.2)$ & $41(85.4)$ & $39(81.3)$ \\
\hline Mean weight, $\mathrm{kg}( \pm \mathrm{SD})$ & $94.1 \pm 19.4$ & $92.3 \pm 24.2$ & $95.8 \pm 19.0$ & $91.6 \pm 19.8$ \\
\hline $\begin{array}{l}\text { Mean body mass index, } \mathrm{kg} / \mathrm{m}^{2} \\
( \pm S D)\end{array}$ & $33.3 \pm 5.4$ & $32.1 \pm 5.8$ & $33.1 \pm 5.7$ & $32.4 \pm 5.6$ \\
\hline Mean $\mathrm{HbA}_{1 c} \%( \pm \mathrm{SD})$ & $7.9 \pm 0.7$ & $8.1 \pm 0.7$ & $8.1 \pm 0.7$ & $7.9 \pm 0.7$ \\
\hline $\begin{array}{l}\text { Mean metformin dose, } \mathrm{mg} \\
\quad( \pm \mathrm{SD})\end{array}$ & $1652 \pm 451$ & $1625 \pm 518$ & $1647 \pm 445$ & $1693 \pm 513$ \\
\hline $\begin{array}{l}\text { Mean years since diagnosis } \\
\quad( \pm \mathrm{SD})\end{array}$ & $7.3 \pm 6.2$ & $7.7 \pm 5.4$ & $8.3 \pm 6.8$ & $8.2 \pm 6.0$ \\
\hline FPG, mg/dl ( \pm SD) & $163.9 \pm 39.0$ & $162.8 \pm 44.0$ & $163.4 \pm 41.1$ & $167.4 \pm 36.3$ \\
\hline $\mathrm{HDL}-\mathrm{C}, \mathrm{mg} / \mathrm{dl}( \pm \mathrm{SD})$ & $48.8 \pm 13.6$ & $52.9 \pm 13.8$ & $46.4 \pm 11.6$ & $48.8 \pm 14.8$ \\
\hline $\mathrm{TG}, \mathrm{mg} / \mathrm{dl}( \pm \mathrm{SD})$ & $185.4 \pm 111.0$ & $157.5 \pm 104.9$ & $195.8 \pm 143.6$ & $163.8 \pm 96.8$ \\
\hline Non-HDL-C, mg/dl ( $(\mathrm{SD})$ & $134.7 \pm 37.3$ & $116.4 \pm 31.7$ & $134.1 \pm 48.8$ & $117.0 \pm 36.1$ \\
\hline
\end{tabular}

Table 2. Placebo-subtracted changes from baseline at 6 months. Data are presented as LSM (least squares mean) changes (95\% Cl).

\begin{tabular}{|c|c|c|c|}
\hline & $\begin{array}{c}\text { TTP399 }(400 \mathrm{mg}) \\
(n=50)\end{array}$ & $\begin{array}{c}\text { TTP399 (800 mg) } \\
\quad(n=42)\end{array}$ & $\begin{array}{l}\text { Sitagliptin } \\
\quad(n=49)\end{array}$ \\
\hline $\mathrm{HbA}_{1 c} \%$ & $-0.2(-0.8$ to 0.5$)$ & $-0.9(-1.5 \text { to }-0.3)^{* *}$ & $-1.0(-1.5$ to -0.5$)$ \\
\hline $\mathrm{FPG}, \mathrm{mg} / \mathrm{dl}$ & $5.5(-19.6$ to 30.5$)$ & $-4.8(-31.0$ to 21.5$)$ & $-16.6(-41.8$ to 8.6$)$ \\
\hline Weight, kg & $-0.11(-1.6$ to 1.4$)$ & $-1.2(-2.7$ to 0.3$)$ & $0.5(-1.0$ to 1.9$)$ \\
\hline Weight in patients $\geq 100 \mathrm{~kg}$ & $-0.2(-2.7$ to 2.4$)$ & $-3.4(-6.2 \text { to }-0.6)^{*}$ & $-0.6(-3.1$ to 2.0$)$ \\
\hline Insulin, $\mu \mathrm{IU} / \mathrm{ml}$ & $0.67(-4.3$ to 5.6$)$ & $1.22(-4.4$ to 6.9$)$ & $-1.3(-7.3$ to 4.7$)$ \\
\hline GLP-1, ng/liter & $10.6(-12.7$ to 33.8$)$ & $0.4(-15.1$ to 15.9$)$ & $18.2(3.3$ to 33.0$)$ \\
\hline C-peptide, $\mu$ g/liter & $0.05(-0.60$ to 0.70$)$ & $-0.19(-0.82$ to 0.44$)$ & $0.23(-0.38$ to 0.85$)$ \\
\hline \multicolumn{4}{|l|}{ Lipids } \\
\hline $\mathrm{HDL}-\mathrm{C}, \mathrm{mg} / \mathrm{dl}$ & $-0.4(-3.4$ to 2.6$)$ & $3.2(0.2 \text { to } 6.1)^{*}$ & $0.9(-1.9$ to 3.7$)$ \\
\hline Lactate, mg/dl & $0.71(-2.5$ to 3.9$)$ & $0.93(-2.3$ to 4.1$)$ & $0.68(-2.4$ to 3.8$)$ \\
\hline
\end{tabular}

${ }^{*} P<0.05 . \quad * * P<0.01$.

these candidates have been discouraging, with reports of increased TG concentrations and systolic blood pressure, and in longer-term clinical trials, loss of efficacy over time $(23,39,40)$.

Numerous reports of rare variants or mutations affecting GKRP expression, localization, and/or activity indicate that these mutations affect not only glucose homeostasis but also TG metabolism (14-19). These findings suggest that interference with normal GK-GKRP in- teractions, as has been reported with previous compounds, may explain the dyslipidemia and possibly the loss of efficacy over time observed with these compounds $(23,26)$.

TTP399 is a hepatoselective GKA that does not interfere with the interaction between GK and GKRP. In addition, it has not demonstrated the risk of hypoglycemia associated with GKA activity in the pancreas. The compound also avoids the AEs of previous GKAs on 
A
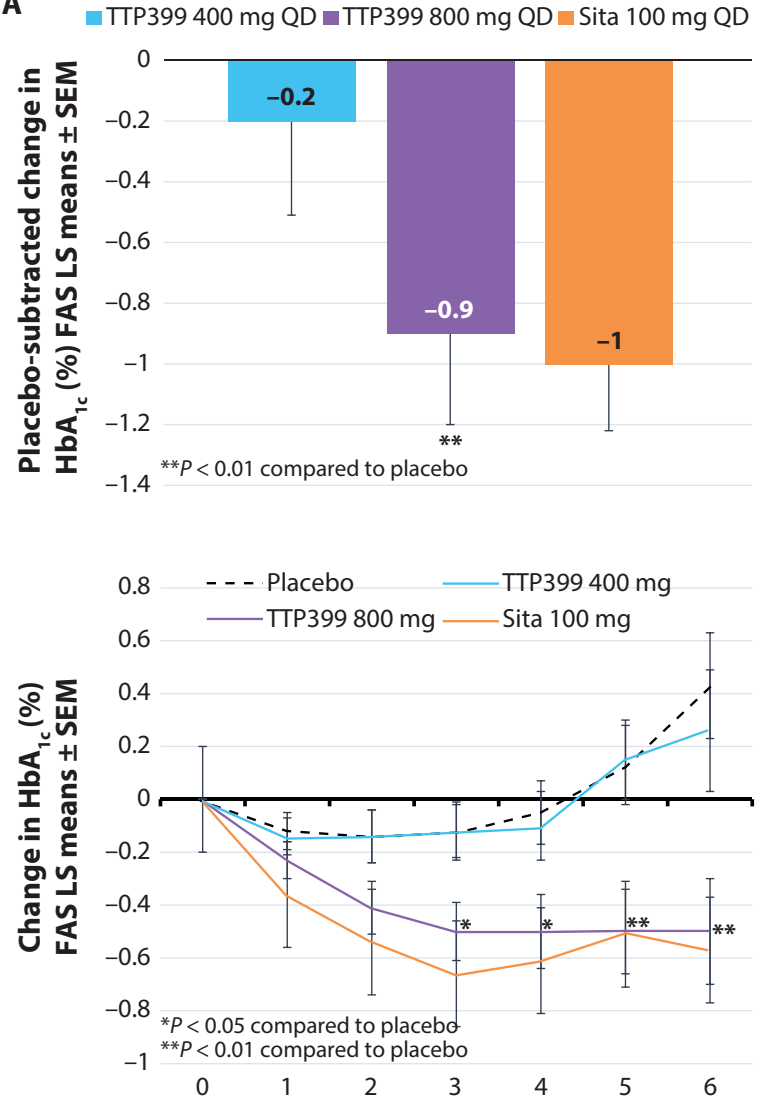
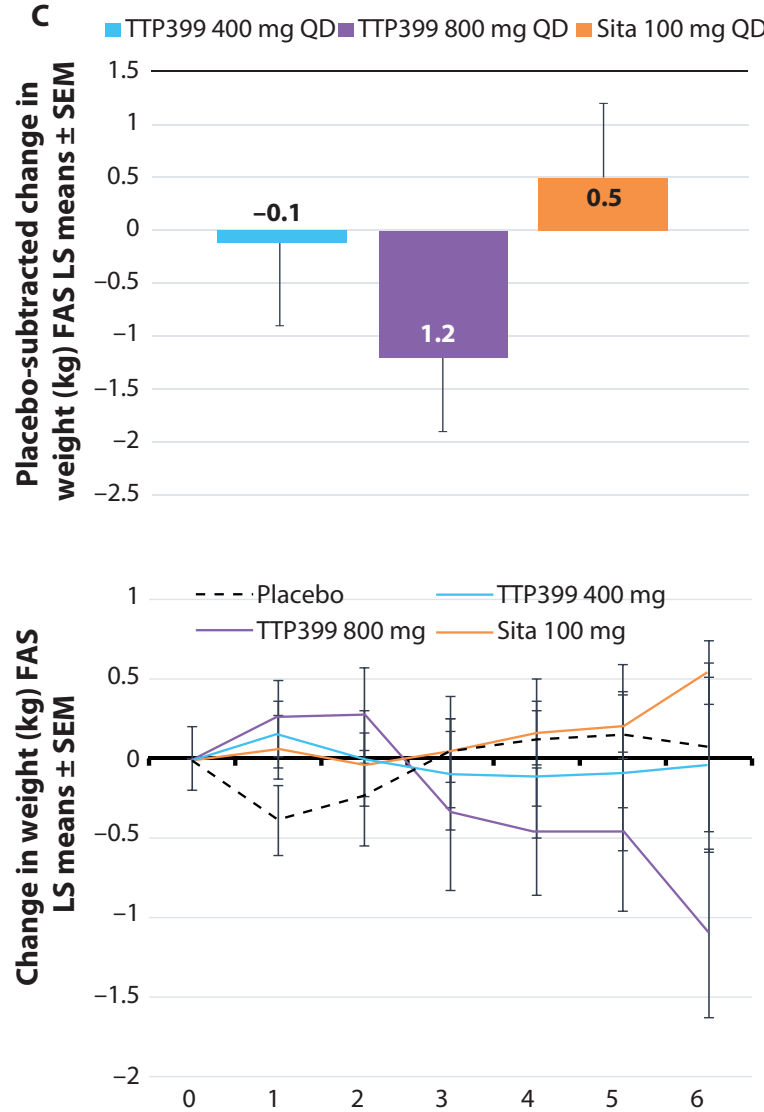

B

TTP399 $800 \mathrm{mg}$ QD

- Sitagliptin $100 \mathrm{mg}$ QD

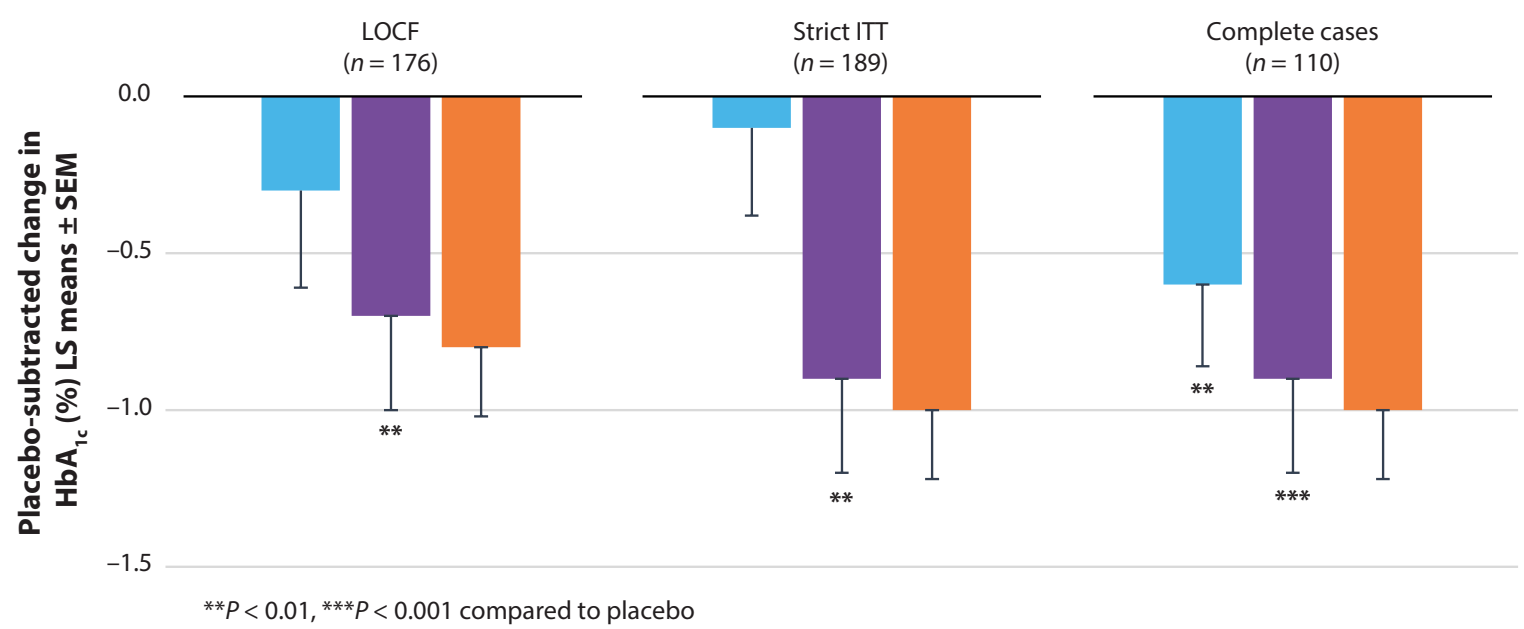

Fig. 5. Changes in $\mathrm{HbA}_{1 \mathrm{c}}$ and body weight at month 6 and over time. (A) Changes in $\mathrm{HbA}_{1 \mathrm{c}}$ at month 6 (top) and over time (bottom) ( $\left.n=171\right)$. QD, once daily; FAS, full analysis set; sita, sitagliptin. (B) Placebo-subtracted change in $\mathrm{HbA}_{1 \mathrm{c}}$ at month 6. (C) Changes in body weight at month 6 (top) and over time (bottom) ( $\left.n=174\right)$. Data are presented as least squares (LS) means \pm SEM. $P$ values based on analysis of covariance (ANCOVA) model with treatment group as a factor and baseline value as a covariate.

the lipid profile. This clinical profile of TTP399 has been confirmed in our phase 2 trial and is consistent with the preclinical data.

Animal studies have demonstrated that TTP399 does not activate GK in pancreatic $\beta$ cells, does not alter insulin secretion, and does not result in hypoglycemia. Therefore, the liver selectivity of
TTP399 obviates concerns regarding the large increases in insulin secretion and the severe and prolonged hypoglycemia that have been observed with dual-acting GKAs $(25,33,34,40)$. Studies of TTP399 in rat hepatocytes also support the hypothesis that the physiological regulation of GK by GKRP, and therefore glucose, in 
Table 3. Adverse events. Data are provided as $n(\%)$.

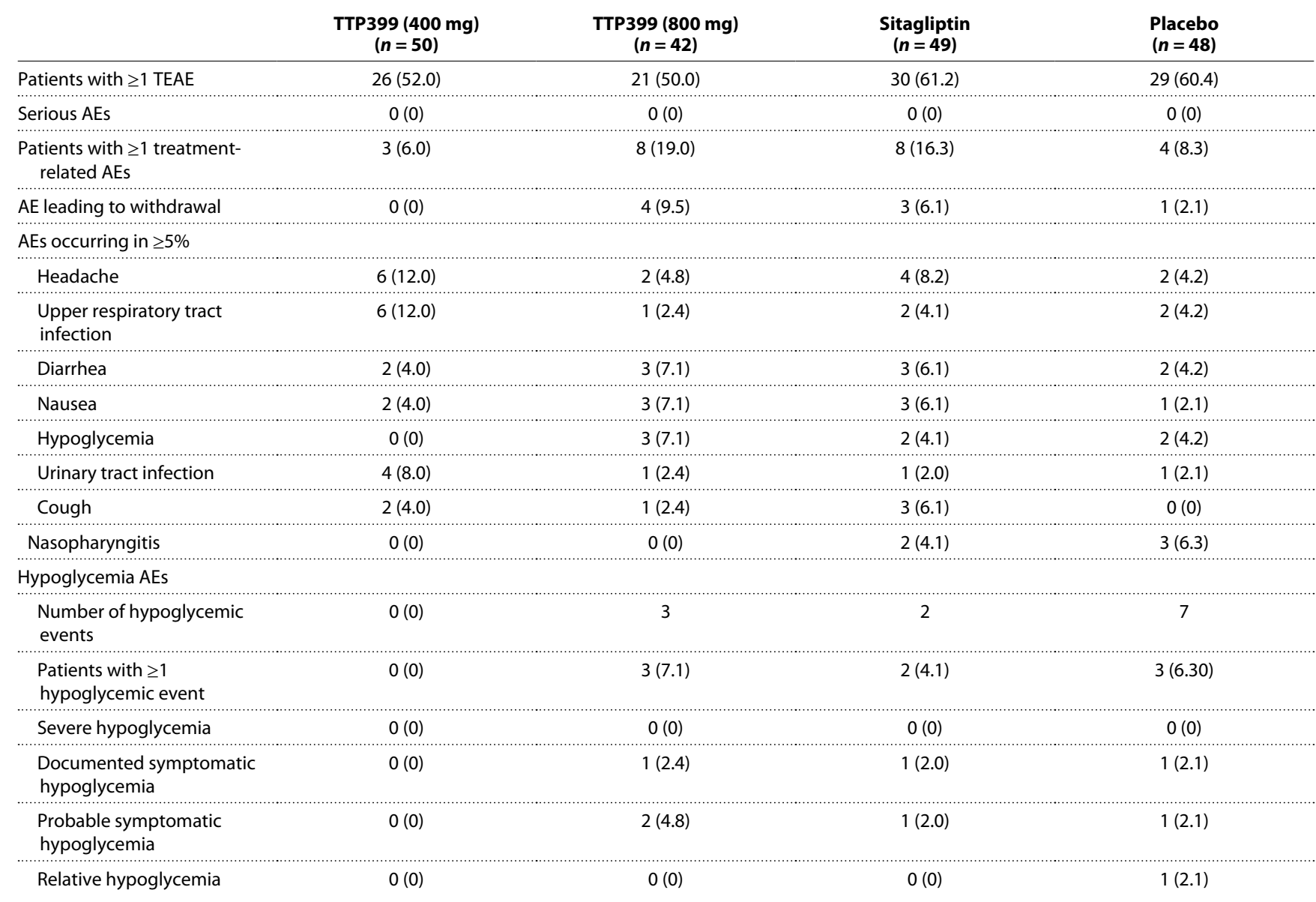

the liver is maintained in the presence of TTP399; as a result, no increase in hepatic TG concentrations in preclinical studies or plasma TG concentrations in clinical studies was observed. The preservation of the GK-GKRP interaction in the presence of TTP399 appears to be particular to this GKA and may be the result of screening compounds for activity in the presence of $15 \mathrm{mM}$ glucose. This screening strategy was used to identify TTP399 selected for compounds that increased the activity of GK when it was in the active conformation. This strategy contrasts with the approaches used for other GKAs, which were identified by screening at 2 to $5 \mathrm{mM}$ glucose, where GK is in the open, or inactive, conformation. Although data using recombinant purified proteins to show that TTP399 does not disrupt the GK-GKRP complex in vitro are not available, evidence of a lack of interference with the GK-GKRP interaction was provided by the nuclear-cellular localization studies, which showed similar nuclear localization at drug concentrations above the $\mathrm{EC}_{50}$ and glucose concentrations spanning a range of 5 to $25 \mathrm{mM}$. These results contrast with observations with dual-acting compounds $(41,42)$ or compounds specifically designed to interrupt the GK-GKRP interaction (43) and may explain the lack of lipid accumulation in the livers of animals treated with TTP399 when compared with dual-acting compounds (25).

Animal models presented here have confirmed that TTP399 improves glycemic control, reduces insulin resistance, and decreases body weight without changes in plasma insulin or hepatic lipids. The reduction in TG observed with TTP399 contrasts with the increase in liver and plasma TG observed in animal models with dual-acting GKAs (25). Moreover, in animal models with dyslipidemia and fatty liver (for example, ob/ob mice), TTP399 reduced TG concentration in both plasma and liver.

Results from the preclinical program supported the initiation of clinical trials investigating TTP399 at doses of up to $800 \mathrm{mg}$ twice daily. Together, these studies included more than 500 participants and reported no signals related to hypoglycemia, hyperlipidemia, or liver toxicity. In these trials, no notable AEs were observed and no serious treatment-related AEs were reported.

In the current phase 2 trial, TTP399 $(800 \mathrm{mg}$ ) produced a placebosubtracted $0.9 \%$ reduction in $\mathrm{HbA}_{1 \mathrm{c}}$ at 6 months. This $\mathrm{HbA}_{1 \mathrm{c}}$ reduction was sustained from months 3 to 6 of the 6 -month study. In contrast, previous studies of GKAs that are not hepatoselective have suggested that their glycemic effects are not sustained $(23,44)$. As was observed in preclinical studies, TTP399 $(800 \mathrm{mg})$ was also associated with low rates of hypoglycemia, a favorable lipid profile (including increased HDL-C), and the potential for weight loss, especially in individuals weighing $100 \mathrm{~kg}$ or more. The observed weight loss in these individuals was consistent with the results of a post hoc analysis of a previous study that had shown loss of body weight among patients with 
baseline body weight of $100 \mathrm{~kg}$ or more (27). The mechanism for the observed weight loss with TTP399 in heavier individuals and the potential impact of TTP399 on appetite and food intake require additional study.

In addition, the reduction in plasma glucagon with TTP399 and its lack of effect on fasting GLP-1 distinguish its mechanism of action from those of sitagliptin and other antidiabetic agents. The reduction in fasting plasma glucagon with TTP399 is intriguing. Elevation of glucagon in prediabetes and diabetes has been attributed to impaired insulin secretion. However, several cohorts have challenged that notion, suggesting that elevated glucagon is associated with impaired insulin signaling $(45,46)$. Ceramide accumulation in the $\alpha$ cells of $o b / o b$ hyperglycemic rodents impairs glucagon suppression (47). Lowering of fasting glucose by TTP399 without change in insulin concentrations implies an improvement in insulin action (46). Whether this mechanism can explain the lowering of fasting glucagon will require further study.

Data from this trial and results of previous studies confirm that, unlike other GKAs that are not hepatoselective, TTP399 does not induce hypoglycemia; has a negligible effect on TG, non-HDL-C, and total cholesterol; has no effect on liver enzymes; and does not increase blood pressure. The reduction in $\mathrm{HbA}_{1 \mathrm{c}}$ with TTP399 $(800 \mathrm{mg})$ was similar to those seen with non-hepatoselective GKAs $(40,44)$, suggesting that the lack of hypoglycemia and the favorable lipid profile associated with TTP399 cannot be explained by a reduction in potency.

Although this trial demonstrated sustained glycemic effects, additional studies will be needed to determine whether the efficacy can be maintained in longer-term applications. In addition, the long-term safety profile of TTP399 will need to be determined.

The totality of the evidence from our preclinical and clinical research and the results from the phase $2 \mathrm{~b}$ trial indicate that TTP399 may have a superior profile compared to other GKAs, suggesting that TTP399 may be a therapeutically viable member of this class. These findings also underscore the importance of tissue selectivity and the preservation of physiological regulation when targeting key metabolic regulators such as GK. Additional research on the effects of TTP399 in a larger clinical trial is needed to confirm these promising results.

\section{MATERIALS AND METHODS Phase 2 clinical trial Study design}

This phase 2, randomized, double-blind, placebo- and active-controlled, parallel group study aimed to evaluate the effect of TTP399 on $\mathrm{HbA}_{1 \mathrm{c}}$ after 6 months of treatment. Twenty-one academic, clinical, and research-based centers in the United States participated in the study. The protocol and informed consent forms were reviewed and approved by each site's institutional review board before initiation of any study activities. After screening, participants were stratified into two groups on the basis of their $\mathrm{HbA}_{1 \mathrm{c}}$ at screening $(\leq 8.0 \%$ versus $>8.0 \%$ ) and were randomized using a site-based scheme to oral TTP399 (800 mg/day), TTP399 (400 mg/day), sitagliptin (100 mg/day; JANUVIA, Merck \& Co.), or placebo. A double-dummy technique was used to mask the active treatments.

Participants were instructed to take their assigned study medication orally at about the same time every day, just before breakfast, for the 6-month treatment period, and continued their current metformin regimen throughout the duration of the study. In the event of hyperglycemia, the initiation and choice of rescue medication were subject to the preference of the investigator. Participants who experienced hyperglycemia were discharged from the study.

The study included a total of nine outpatient visits. The screening visit occurred within 1 week before randomization, seven visits occurred during treatment at intervals of about 28 days, and the follow-up visit occurred about 2 weeks after the eighth visit.

\section{Participants}

This study enrolled adults aged 18 to 75 years who had been diagnosed with type 2 diabetes at least 6 months before screening, were using a stable dose of metformin of at least $1000 \mathrm{mg} /$ day for at least the last 3 months, had an $\mathrm{HbA}_{1 \mathrm{c}}$ level of $\geq 7.0$ and $\leq 9.5 \%$, and had a body mass index between 20 and $45 \mathrm{~kg} / \mathrm{m}^{2}$. Participants were excluded if they had renal insufficiency (estimated glomerular filtration rate of less than $50 \mathrm{ml} / \mathrm{min}$ per $1.73 \mathrm{~m}^{2}$ ); had used any antidiabetic agent other than metformin within 3 months; were using other medications known to affect glucose metabolism; had a history of myocardial infarction, unstable angina, coronary revascularization, stroke, or transient ischemic attack within 2 years; or had symptomatic congestive heart failure. Patients with a history of serious cardiac arrhythmias or cardiac arrhythmias requiring treatment or prophylaxis, second- or third-degree heart block, or atrial fibrillation lasting more than 2 days were also excluded, as were patients with clinically significant disease viewed by the investigator or a medical monitor to make the patient inappropriate for the trial.

\section{Biochemical and clinical assessments}

Routine clinical laboratory evaluations, including assessments of hematology, chemistry, thyroid-stimulating hormone, insulin, C-peptide, and lipids, as well as monitoring of $\mathrm{HbA}_{1 \mathrm{c}}$, plasma glucose, lactate, glucagon, and GLP-1, were conducted at each post-baseline visit. Assessments of compliance and safety (via analysis of AE reports) were also conducted.

\section{Statistical analysis}

Assuming an SD of 1\%, 44 participants per group would provide $90 \%$ power to detect a difference of $0.7 \%$ in $\mathrm{HbA}_{1 \mathrm{c}}$ between a group treated with TTP399 and a group treated with placebo, using $\alpha=0.05$. On the basis of these assumptions, it was thought that the randomization of 180 participants [randomized in balanced allocation to TTP399 (400 mg) once daily, TTP399 (800 mg) once daily, sitagliptin (100 mg) once daily, or placebo once daily] would provide adequate power for this study to meet its objectives.

\section{Efficacy evaluation}

Efficacy was evaluated following ITT principles, which followed the protocol-specified conditional sequence of hypothesis tests to control $\alpha$. The statistical model for the primary analysis used an ANCOVA main-effects model with baseline $\mathrm{HbA}_{1 \mathrm{c}}$ as a covariate on change from baseline to month 6 in $\mathrm{HbA}_{1 \mathrm{c}}$ on the full analysis set (all randomized participants with on-treatment data).

Multiple imputation methods were used to handle missing data. To ensure robustness of the conclusions of the analysis, we conducted additional supportive analyses, including an LOCF analysis for handling missing data and a complete-cases analysis. Sensitivity analyses included rank analogues to ensure robustness of analysis conclusions to the inclusion of covariables, the parametric assumptions, the choice of the statistical model, or methodology for coping with missing data. A strict ITT analysis was also conducted using data from all randomized participants, regardless of whether participants received treatment or had posttreatment data. Statistical comparisons with sitagliptin were not planned, consistent with $\alpha$-spending rules allocating full $\alpha$ to comparisons between TTP399 and placebo and consistent 
with the inclusion of sitagliptin for assay sensitivity. In this study, no $\alpha$ was allocated to comparisons with sitagliptin.

\section{Safety evaluation}

All safety analyses were based on the safety set, which included all participants who received at least one dose of study medication. Continuous safety variables were summarized using descriptive statistics.

\section{Preclinical studies}

All preclinical animal research was performed in concordance with local and national regulations.

Transporter-mediated uptake into rat hepatocytes and pancreatic $\beta$ cells in vitro

Primary rat hepatocytes were prepared from Sprague-Dawley rats and cultured as described in the Supplementary Materials. Time, temperature, and concentration dependence studies were performed as in Ismair et al. (48).

Rat INS-1E $\beta$ cells were cultured as described in the Supplementary Materials. After 2 to 3 days, uptake experiments were performed. Cell monolayers were washed with uptake buffer $(100 \mathrm{mM} \mathrm{NaCl}$, $2 \mathrm{mM} \mathrm{KCl}$, and $1 \mathrm{mM}$ Hepes adjusted to $\mathrm{pH} 7.4$ with $\mathrm{NaOH}$ ) for $30 \mathrm{~min}$ at $37^{\circ} \mathrm{C}$. The experiment was initiated by the addition of $500 \mu \mathrm{l}$ of TTP399 spiked with $\left[{ }^{14} \mathrm{C}\right]$-TTP399 $(0.02 \mu \mathrm{Ci}$ per well). The concentration of TTP399 varied between 1 and $200 \mu \mathrm{M}$. After incubation ( 0 to $30 \mathrm{~min}$ ), the uptake was stopped by aspiration of the uptake buffer, followed by three rapid washes with ice-cold buffer. The cells were lysed overnight, and uptake was determined by liquid scintillation counting.

\section{Hepatic glucose metabolism in vitro}

Rat primary hepatocytes were obtained and cultured as described above and plated onto collagen-coated 24-well plates at a density of 200,000 cells per well. The culture medium was changed after 1 hour to remove dead cells and again after 24 hours, when it was supplemented with $0.5 \mathrm{mM}$ glucose and $10 \mathrm{nM}$ insulin to induce glycogen synthesis. Twenty four hours later, the metabolism studies were performed. The hepatocytes were washed twice with GlycoBuffer [117.6 mM NaCl, 5.4 mM KCl, $0.82 \mathrm{mM} \mathrm{Mg}_{2} \mathrm{SO}_{4}, 1.5 \mathrm{mM} \mathrm{KH}_{2} \mathrm{PO}_{4}$, $20 \mathrm{mM}$ Hepes, $9 \mathrm{mM} \mathrm{NaHCO}, 0.1 \%$ (w/v) human serum albumin, and $2.25 \mathrm{mM} \mathrm{CaCl}_{2}(\mathrm{pH} 7.4)$ at $37^{\circ} \mathrm{C}$. The cells were incubated for 3 hours in $500 \mu \mathrm{l}$ of this buffer containing $15 \mathrm{mM}$ glucose, $1 \mathrm{nM}$ insulin, and concentrations of TTP399 ranging from 0 to $25 \mu \mathrm{M}$. At the end of the incubation period, buffer was sampled for determination of lactate concentration. The cells were washed with cold $0.9 \%$ $\mathrm{NaCl}$ and lysed by freezing and thawing. Cellular glycogen was enzymatically hydrolyzed in situ by incubating cells for 2 hours with amyloglucosidase $(50 \mathrm{U} / \mathrm{ml})$ diluted in $0.2 \mathrm{M}$ sodium acetate buffer ( $\mathrm{pH} 4.8$ ). After hydrolysis, $40 \mu \mathrm{l}$ of buffer was transferred to a 96well plate, and samples were neutralized by adding $0.25 \mathrm{mM} \mathrm{NaOH}$. Glucose was measured with the hexokinase/glucose-6-phosphate dehydrogenase enzymatic assay. Protein content in culture dishes was determined after solubilization in $0.4 \mathrm{M} \mathrm{KOH}$ using a BioRad protein assay and human serum albumin as the standard. Results were expressed as percentage of increase in glycogen content compared with control hepatocytes.

In vitro effect on insulin secretion in mouse pancreatic islet cells Mouse islets were isolated and cultured as described in the Supplementary Materials. Batches of 10 islets were preincubated in Krebs-Ringer bicarbonate Hepes buffer (KRBH) supplemented with $3 \mathrm{mM}$ glucose for $30 \mathrm{~min}$, followed by 60 -min incubation in $\mathrm{KRBH}$ with TTP399. Islets were then superfused after being added on top of a column consisting of $0.3 \mathrm{ml}$ of Bio-Gel P-2 at a rate of $0.35 \mathrm{ml} / \mathrm{min}$. The supernatant was collected in 96-well plates, and insulin was quantified by radioimmunoassay using rat insulin as the standard.

\section{GK translocation}

Fresh isolated primary rat hepatocytes were plated and cultured as described in the Supplementary Materials. Hepatocytes were treated with 1 or $3 \mu \mathrm{M}$ TTP399 or dimethyl sulfoxide in the presence of 5, 15 , or $25 \mathrm{mM}$ glucose for 1 hour. After 1-hour treatment, cells were washed in phosphate-buffered saline (PBS), then fixed in $4 \%$ paraformaldehyde (PFA) in PBS for 10 min, washed twice with PBS, and then permeabilized with $0.1 \%$ Triton X-100 in PBS for 5 min. Afterward, cells were blocked in a PBS solution containing 5\% bovine serum albumin (BSA) and $0.05 \%$ Triton X-100. Cells were probed with rabbit anti-GK antibody (H-88; sc7908, Santa Cruz Biotechnology) in PBS containing 1\% BSA and $0.01 \%$ Triton X-100 for 1 hour, washed twice, and then probed with secondary goat anti-rabbit Alexa Fluor 488 antibody plus the nuclear stain Hoechst (Invitrogen) for 1 hour. Stained cells were washed in PBS, and fluorescence was detected using the IN Cell Analyzer 2000 instrument (GE Healthcare Life Sciences). To detect the translocation of GK, the nuclear and cellular intensity of GK was determined using the multitarget analysis protocol (IN Cell analyzer software).

\section{In vivo effect on plasma glucose and insulin}

Wistar rats, in which indwelling arterial and venous catheters had previously been placed, were fasted overnight with free access to water. Arterial blood samples $(115 \mu \mathrm{l})$ were taken before and at 15 , $30,45,60,75,90,120,150,180$, and $240 \mathrm{~min}$ after dosing. Rats were dosed orally with vehicle $(n=7)$, TTP399 $(n=7200 \mathrm{mg} / \mathrm{kg})$, or NNC80-0000-3281 ( $n=4200 \mathrm{mg} / \mathrm{kg}$, a nonliver-selective GKA). Blood samples were anticoagulated with EDTA and then centrifuged at $4^{\circ} \mathrm{C}$. Plasma $(10 \mu \mathrm{l})$ was removed for determination of plasma glucose, and two $20 \mu \mathrm{l}$ aliquots were frozen on dry ice and kept at $-80 \stackrel{\circ}{\rightarrow} \mathrm{C}$ until they were assayed for plasma insulin concentrations.

\section{Ob/ob mice}

Male Umeå ob/ob mice, 9 to 11 weeks of age, were allocated into three groups ( $n=14$ per group) and were orally treated with vehicle ( $0.5 \%$ carboxymethylcellulose in water) or TTP399 $(75$ or $150 \mathrm{mg} / \mathrm{kg}$ per day) for 28 consecutive days. An additional group of nontreated lean $(\mathrm{ob} /+$ or $+/+)$ mice was included as comparators. Body weight and $\mathrm{HbA}_{1 \mathrm{c}}$ were recorded weekly. Thirty-hour blood glucose and lactate profiles were obtained after the first and 22nd dose. Body composition (body fat), as determined by magnetic resonance scan, and blood insulin, leptin, and glucagon concentrations were measured before the start of treatment and at termination of dosing. At termination, blood was taken for analysis of $\mathrm{HbA}_{1 \mathrm{c}}$, insulin, glucose, leptin, glucagon, TGs, total cholesterol, HDL-C, free fatty acids, AST, and ALT. Livers were collected for determination of TGs, glycogen, GK protein content, and GK activity. The pancreata were excised, fixed in $4 \%$ PFA, fractionated by the "smooth fractionator" method (49), dehydrated, embedded in paraffin, sectioned, and stained for $\beta$ cells and non- $\beta$ cells. $\beta$ Cell and non- $\beta$ cell mass was determined by point counting stereological technique from two sections cut $250 \mu \mathrm{m}$ apart by an observer blinded to the origin of the slides (49).

\section{Gottingen minipigs}

Eight male and eight female Gottingen minipigs (Marshall BioResources), about 4 months of age, were randomized into groups of four minipigs per sex per group, and either vehicle [0.5\% hydroxypropyl 
methylcellulose and 5\% polyethylene glycol 400 (PEG-400) in water] or TTP399 (50 mg/kg per day) was administered orally for 91 consecutive days. Body weights were recorded weekly. Blood samples for evaluation of lactic acid and TG concentrations were collected from all animals (fasted) pretest and 2 hours after a dose on days 30, 60, and 91. At study termination, liver samples were collected for evaluation of free glycerol, TG, and glycogen concentrations.

OGTTs were performed in three minipigs after treatment with metformin alone or metformin + TP399. Before the day of the meal challenge, minipigs were dosed for 7 days with twice-daily oral metformin (500 $\mathrm{mg}$ per dose) to mimic the clinical scenario of administering TTP399 to patients on stable doses of metformin. Both drugs were administered by oral gavage, with TTP399 suspended in a vehicle of $0.5 \%$ hydroxypropyl methylcellulose and 5\% PEG-400 in distilled water and with ground metformin tablets suspended in $0.5 \%$ Tween 80 and $0.2 \%$ hydroxyethyl cellulose in $0.05 \mathrm{M}$ sodium phosphate buffer ( $\mathrm{pH}$ 8). Each formulation was administered at a dose volume of $5 \mathrm{ml} / \mathrm{kg}$. One hour after treatment, each minipig received a glucose ( $1 \mathrm{~g} / \mathrm{kg}$; Karo Syrup) and food challenge (Certified Block Diet catalog no. 8753C, Harlan Sprague Dawley Inc.). Venous blood samples were taken before treatment, 1 hour after treatment (and before feeding), and 0.5, $1,2,5$, and 9 hours after the glucose and food challenge for determination of blood glucose and insulin concentrations.

\section{Glucose and insulin determinations}

Plasma glucose was measured with a glucometer. Plasma insulin concentrations were determined using species-specific solid phase two-site enzyme immunoassay on the basis of the sandwich technique. Standard samples were run in triplicate, and experimental samples were run in duplicate.

\section{Statistical analysis}

All experiments were performed in at least triplicate biological repeats, with data presented as means \pm SEM, unless otherwise stated. For GK nuclear translocation in rat hepatocytes, significance was determined with the use of one-way analysis of variance (ANOVA), followed by Dunnett's multiple comparison test. For experiments in ob/ob mice and Gottingen minipigs, statistical significance was assessed by group comparison with the use of one-way ANOVA, followed by Tukey's post hoc test. For all, statistical significance was accepted at $P<0.05$.

\section{SUPPLEMENTARY MATERIALS}

www.sciencetranslationalmedicine.org/cgi/content/full/11/475/eaau3441/DC1 Materials and Methods

Fig. S1. The effect of TTP399 on GK activity.

Fig. S2. TTP399 stimulation of glucose metabolism in isolated rat hepatocytes.

Fig. S3. Differential uptake of TTP399 into rat hepatocytes and $\beta$ cells.

Fig. S4. The effect of TTP399 on $\mathrm{HbA}_{1 \mathrm{c}}$ concentrations in diabetic Umeå ob/ob mice.

Fig. S5. Liver TG content in diabetic Umeå ob/ob mice after 4 weeks of treatment with TTP399.

Fig. S6. Effect of 4 weeks of treatment with TTP399 on body weight and food intake in diabetic Umeå ob/ob mice.

Fig. S7. The effect of metformin alone or metformin + TTP399 on blood glucose and insulin levels in Gottingen minipigs.

Fig. S8. Metabolic changes at month 6 and over time.

Table S1. Area under the plasma glucose concentration-time curve after doses of TTP399 on days 1 and 22 in diabetic Umeå ob/ob mice.

Table S2. Plasma insulin concentration before treatment and after 22 days of treatment in diabetic Umeå ob/ob mice.

Table S3. Plasma concentrations of TGs and lactic acid during treatment with TTP399 in Gottingen minipigs.

Table S4. Hepatic-free glycerol, TGs, and glycogen content after 3 months of treatment with TTP399 (50 mg/kg per day) in Gottingen minipigs.

Reference (50)

\section{REFERENCES AND NOTES}

1. G. Smushkin, A. Vella, Genetics of type 2 diabetes. Curr. Opin. Clin. Nutr. Metab. Care 13, 471-477 (2010).

2. D. M. Irwin, H. Tan, Evolution of glucose utilization: Glucokinase and glucokinase regulator protein. Mol. Phylogenet. Evol. 70, 195-203 (2014).

3. D. Fu, X. Cong, Y. Ma, H. Cai, M. Cai, D. Li, M. Lv, X. Yuan, Y. Huang, Z. Lv, Genetic polymorphism of glucokinase on the risk of type 2 diabetes and impaired glucose regulation: Evidence based on 298,468 subjects. PLOS ONE 8, e55727 (2013).

4. M. M. Byrne, J. Sturis, K. Clement, N. Vionnet, M. E. Pueyo, M. Stoffel, J. Takeda, P. Passa, D. Cohen, G. I. Bell, Insulin secretory abnormalities in subjects with hyperglycemia due to glucokinase mutations. J. Clin. Invest. 93, 1120-1130 (1994).

5. L. Agius, Glucokinase and molecular aspects of liver glycogen metabolism. Biochem. J. 414, 1-18 (2008).

6. B. Glaser, P. Kesavan, M. Heyman, E. Davis, A. Cuesta, A. Buchs, C. A. Stanley, P. S. Thornton, M. A. Permutt, F. M. Matschinsky, K. C. Herold, Familial hyperinsulinism caused by an activating glucokinase mutation. N. Engl. J. Med. 338, 226-230 (1998).

7. F. M. Matschinsky, B. Glaser, M. A. Magnuson, Pancreatic $\beta$-cell glucokinase: Closing the gap between theoretical concepts and experimental realities. Diabetes 47, 307-315 (1998).

8. P. B. Iynedjian, Molecular physiology of mammalian glucokinase. Cell. Mol. Life Sci. 66, 27-42 (2009).

9. A. Basu, R. Basu, P. Shah, A. Vella, C. M. Johnson, M. Jensen, K. S. Nair, W. F. Schwenk, R. A. Rizza, Type 2 diabetes impairs splanchnic uptake of glucose but does not alter intestinal glucose absorption during enteral glucose feeding: Additional evidence for a defect in hepatic glucokinase activity. Diabetes 50, 1351-1362 (2001).

10. K. D. Niswender, C. Postic, M. Shiota, T. L. Jetton, M. A. Magnuson, Effects of altered glucokinase gene copy number on blood glucose homoeostasis. Biochem. Soc. Trans. 25, 113-117 (1997).

11. A. Vandercammen, E. Van Schaftingen, The mechanism by which rat liver glucokinase is inhibited by the regulatory protein. Eur. J. Biochem. 191, 483-489 (1990).

12. A. Vandercammen, E. Van Schaftingen, Competitive inhibition of liver glucokinase by its regulatory protein. Eur. J. Biochem. 200, 545-551 (1991).

13. A. Vandercammen, E. Van Schaftingen, Species and tissue distribution of the regulatory protein of glucokinase. Biochem. J. 294 (Pt. 2), 551-556 (1993).

14. Diabetes Genetics Initiative of Broad Institute of Harvard and MIT, Lund University, and Novartis Institutes of BioMedical Research, R. Saxena, B. F. Voight, V. Lyssenko, N. P. Burtt, P. I. W. de Bakker, H. Chen, J. J. Roix, S. Kathiresan, J. N. Hirschhorn, M. J. Daly, T. E. Hughes, L. Groop, D. Altshuler, P. Almgren, J. C. Florez, J. Meyer, K. Ardlie, K. B. Boström, B. Isomaa, G. Lettre, U. Lindblad, H. N. Lyon, O. Melander, C. Newton-Cheh, P. Nilsson, M. Orho-Melander, L. Råstam, E. K. Speliotes, M.-R. Taskinen, T. Tuomi, C. Guiducci, A. Berglund, J. Carlson, L. Gianniny, R. Hackett, L. Hall, J. Holmkvist, E. Laurila, M. Sjögren, M. Sterner, A. Surti, M. Svensson, M. Svensson, R. Tewhey, B. Blumenstiel, M. Parkin, M. DeFelice, R. Barry, W. Brodeur, J. Camarata, N. Chia, M. Fava, J. Gibbons, B. Handsaker, C. Healy, K. Nguyen, C. Gates, C. Sougnez, D. Gage, M. Nizzari, S. B. Gabriel, G.-W. Chirn, Q. Ma, H. Parikh, D. Richardson, D. Ricke, S. Purcell, Genome-wide association analysis identifies loci for type 2 diabetes and triglyceride levels. Science 316, 1331-1336 (2007).

15. M. Orho-Melander, O. Melander, C. Guiducci, P. Perez-Martinez, D. Corella, C. Roos, R. Tewhey, M. J. Rieder, J. Hall, G. Abecasis, E. S. Tai, C. Welch, D. K. Arnett, V. Lyssenko, E. Lindholm, R. Saxena, P. I. W. de Bakker, N. Burtt, B. F. Voight, J. N. Hirschhorn, K. L. Tucker, T. Hedner, T. Tuomi, B. Isomaa, K.-F. Eriksson, M.-R. Taskinen, B. Wahlstrand, T. E. Hughes, L. D. Parnell, C.-Q. Lai, G. Berglund, L. Peltonen, E. Vartiainen, P. Jousilahti, A. S. Havulinna, V. Salomaa, P. Nilsson, L. Groop, D. Altshuler, J. M. Ordovas, S. Kathiresan, Common missense variant in the glucokinase regulatory protein gene is associated with increased plasma triglyceride and C-reactive protein but lower fasting glucose concentrations. Diabetes 57, 3112-3121 (2008).

16. T. Sparsø, G. Andersen, T. Nielsen, K. S. Burgdorf, A. P. Gjesing, A. L. Nielsen, A. Albrechtsen, S. S. Rasmussen, T. Jørgensen, K. Borch-Johnsen, A. Sandbæk, T. Lauritzen, S. Madsbad, T. Hansen, O. Pedersen, The GCKR rs780094 polymorphism is associated with elevated fasting serum triacylglycerol, reduced fasting and OGTT-related insulinaemia, and reduced risk of type 2 diabetes. Diabetologia 51, 70-75 (2008).

17. M. Vaxillaire, C. Cavalcanti-Proenca, A. Dechaume, J. Tichet, M. Marre, B. Balkau, P. Froguel, DESIR Study Group, The common P446L polymorphism in GCKR inversely modulates fasting glucose and triglyceride levels and reduces type 2 diabetes risk in the DESIR prospective general French population. Diabetes 57, 2253-2257 (2008).

18. N. L. Beer, N. D. Tribble, L. J. McCulloch, C. Roos, P. R. V. Johnson, M. Orho-Melander, A. L. Gloyn, The P446L variant in GCKR associated with fasting plasma glucose and triglyceride levels exerts its effect through increased glucokinase activity in liver. Hum. Mol. Genet. 18, 4081-4088 (2009).

19. C. H. T. Tam, R. C. W. Ma, W. Y. So, Y. Wang, V. K. L. Lam, S. Germer, M. Martin, J. C. N. Chan, M. C. Y. Ng, Interaction effect of genetic polymorphisms in glucokinase (GCK) and glucokinase regulatory protein (GCKR) on metabolic traits in healthy Chinese adults and adolescents. Diabetes 58, 765-769 (2009). 
20. F. M. Matschinsky, Assessing the potential of glucokinase activators in diabetes therapy Nat. Rev. Drug Discov. 8, 399-416 (2009).

21. L. Agius, Targeting hepatic glucokinase in type 2 diabetes: Weighing the benefits and risks. Diabetes 58, 18-20 (2009).

22. A. S. Grewal, B. S. Sekhon, V. Lather, Recent updates on glucokinase activators for the treatment of type 2 diabetes mellitus. Mini Rev. Med. Chem. 14, 585-602 (2014).

23. C. Hale, D. J. Lloyd, A. Pellacani, M. M. Véniant, Molecular targeting of the GK-GKRP pathway in diabetes. Expert Opin. Ther. Targets 19, 129-139 (2015).

24. L. Katz, N. Manamley, W. J. Snyder, M. Dodds, N. Agafonova, J. Sierra-Johnson, M. Cruz, P. Kaur, S. Mudaliar, P. Raskin, R. Kewalramani, A. Pellacani, AMG 151 (ARRY-403), a novel glucokinase activator, decreases fasting and postprandial glycaemia in patients with type 2 diabetes. Diabetes Obes. Metab. 18, 191-195 (2016).

25. F. De Ceuninck, C. Kargar, C. Ilic, A. Caliez, J.-O. Rolin, T. Umbdenstock, C. Vinson, M. Combettes, B. de Fanti, E. Harley, M. Sadlo, A.-L. Lefevre, O. Broux, M. Wierzbicki, J.-M. Fourquez, F. Perron-Sierra, A. Kotschy, A. Ktorza, Small molecule glucokinase activators disturb lipid homeostasis and induce fatty liver in rodents: A warning for therapeutic applications in humans. Br. J. Pharmacol. 168, 339-353 (2013).

26. A. Raimondo, M. G. Rees, A. L. Gloyn, Glucokinase regulatory protein: Complexity at the crossroads of triglyceride and glucose metabolism. Curr. Opin. Lipidol. 26, 88-95 (2015).

27. C. Valcarce, I. Grimes, S. Gustavson, A. H. Burstein, A. Mjalli, TTP399, a liver-selective glucose kinase activator (GKA), lowers glucose and does not increase lipids in subjects with type 2 diabetes mellitus (T2DM). Diabetes 63 (suppl. 1), A32 (2016).

28. C. Valcarce, I. Dunn, J. Freeman, TTP399, a novel, liver selective glucokinase activator: Results from a 10-day pilot study in patients with type 2 diabetes mellitus (T2DM) naïve to drug [abstract]. Diabetes 65 (suppl. 1), A299 (2016).

29. M. Coghlan, B. Leighton, Glucokinase activators in diabetes management. Expert Opin. Investig. Drugs 17, 145-167 (2008).

30. M. S. Winzell, M. Coghlan, B. Leighton, G. Frangioudakis, D. M. Smith, L. H. Storlien, B. Ahrén, Chronic glucokinase activation reduces glycaemia and improves glucose tolerance in high-fat diet fed mice. Eur. J. Pharmacol. 663, 80-86 (2011).

31. K. J. Filipski, J. Bian, D. C. Ebner, E. C. Y. Lee, J.-C. Li, M. F. Sammons, S. W. Wright, B. D. Stevens, M. T. Didiuk, M. Tu, C. Perreault, J. Brown, K. Atkinson, B. Tan, C. T. Salatto, J. Litchfield, J. A. Pfefferkorn, A. Guzman-Perez, A novel series of glucagon receptor antagonists with reduced molecular weight and lipophilicity. Bioorg. Med. Chem. Lett. 22, 415-420 (2012).

32. J. A. Pfefferkorn, Strategies for the design of hepatoselective glucokinase activators to treat type 2 diabetes. Expert Opin. Drug Discov. 8, 319-330 (2013).

33. J.-i. Eiki, Y. Nagata, M. Futamura, K. Sasaki-Yamamoto, T. lino, T. Nishimura, M. Chiba, S. Ohyama, R. Yoshida-Yoshimioto, K. Fujii, H. Hosaka, H. Goto-Shimazaki, A. Kadotani, T. Ohe, S. Lin, R. B. Langdon, J. P. Berger, Pharmacokinetic and pharmacodynamic properties of the glucokinase activator MK-0941 in rodent models of type 2 diabetes and healthy dogs. Mol. Pharmacol. 80, 1156-1165 (2011).

34. N. Dhanesha, A. Joharapurkar, G. Shah, S. Kshirsagar, V. Patel, K. Patel, R. Bahekar, M. Jain, Treatment with exendin-4 improves the antidiabetic efficacy and reverses hepatic steatosis in glucokinase activator treated db/db mice. Eur. J. Pharmacol. 714, 188-192 (2013).

35. F. De Ceuninck, C. Kargar, Y. Charton, S. Goldstein, F. Perron-Sierra, C. Ilic, A. Caliez, J.-O. Rolin, M. Sadlo, E. Harley, C. Vinson, A. Ktorza, S 50131 and S 51434, two novel small molecule glucokinase activators, lack chronic efficacy despite potent acute antihyperglycaemic activity in diabetic mice. Br. J. Pharmacol. 169, 999-1010 (2013).

36. J. C. Pettersen, J. Litchfield, N. Neef, S. P. Schmidt, N. Shirai, K. M. Walters, B. E. Enerson L. A. Chatman, J. A. Pfefferkorn, The relationship of glucokinase activator-induced hypoglycemia with arteriopathy, neuronal necrosis, and peripheral neuropathy in nonclinical studies. Toxicol. Pathol. 42, 696-708 (2014).

37. G. R. Bebernitz, V. Beaulieu, B. A. Dale, R. Deacon, A. Duttaroy, J. Gao, M. S. Grondine, R. C. Gupta, M. Kakmak, M. Kavana, L. C. Kirman, J. Liang, W. M. Maniara, S. Munshi, S. S. Nadkarni, H. F. Schuster, T. Stams, I. St. Denny, P. M. Taslimi, B. Vash, S. L. Caplan, Investigation of functionally liver selective glucokinase activators for the treatment of type 2 diabetes. J. Med. Chem. 52, 6142-6152 (2009).

38. J. A. Pfefferkorn, A. Guzman-Perez, J. Litchfield, R. Aiello, J. L. Treadway, J. Pettersen, M. L. Minich, K. J. Filipski, C. S. Jones, M. Tu, G. Aspnes, H. Risley, J. Bian, B. D. Stevens, P. Bourassa, T. D'Aquila, L. Baker, N. Barucci, A. S. Robertson, F. Bourbonais, D. R. Derksen, M. Macdougall, O. Cabrera, J. Chen, A. L. Lapworth, J. A. Landro, W. J. Zavadoski, K. Atkinson, N. Haddish-Berhane, B. Tan, L. Yao, R. E. Kosa, M. V. Varma, B. Feng, D. B. Duignan, A. El-Kattan, S. Murdande, S. Liu, M. Ammirati, J. Knafels, P. DaSilva-Jardine, L. Sweet, S. Liras, T. P. Rolph, Discovery of (S)-6-(3-cyclopentyl-2-(4-(trifluoromethyl)-1Himidazol-1-yl)propanamido)nicotinic acid as a hepatoselective glucokinase activator clinical candidate for treating type 2 diabetes mellitus. J. Med. Chem. 55, 1318-1333 (2012).

39. D. Kazierad, J. Pfefferkorn, A. Bergman, X. Wang, T. P. Rolph, J. M. Rusnak, The hepatoselective glucokinase activator (GKA) PF-04991532, lowers HbA1c after 12 weeks of dosing in patients with type 2 diabetes (T2DM), in 73rd American Diabetes Conference, Chicago, IL, 21 to 25 June 2013.
40. G. E. Meininger, R. Scott, M. Alba, Y. Shentu, E. Luo, H. Amin, M. J. Davies, K. D. Kaufman B. J. Goldstein, Effects of MK-0941, a novel glucokinase activator, on glycemic control in insulin-treated patients with type 2 diabetes. Diabetes Care 34, 2560-2566 (2011).

41. M. Futamura, H. Hosaka, A. Kadotani, H. Shimazaki, K. Sasaki, S. Ohyama, T. Nishimura, J.-i. Eiki, Y. Nagata, An allosteric activator of glucokinase impairs the interaction of glucokinase and glucokinase regulatory protein and regulates glucose metabolism. J. Biol. Chem. 281, 37668-37674 (2006).

42. O. Anderka, J. Boyken, U. Aschenbach, A. Batzer, O. Boscheinen, D. Schmoll, Biophysical characterization of the interaction between hepatic glucokinase and its regulatory protein: Impact of physiological and pharmacological effectors. J. Biol. Chem. 283, 31333-31340 (2008).

43. D. J. Lloyd, D. J. St. Jean Jr., R. J. M. Kurzeja, R. C. Wahl, K. Michelsen, R. Cupples, M. Chen J. Wu, G. Sivits, J. Helmering, R. Komorowski, K. S. Ashton, L. D. Pennington, C. Fotsch, M. Vazir, K. Chen, S. Chmait, J. Zhang, L. Liu, M. H. Norman, K. L. Andrews, M. D. Bartberger, G. Van, E. J. Galbreath, S. L. Vonderfecht, M. Wang, S. R. Jordan, M. M. Véniant, C. Hale, Antidiabetic effects of glucokinase regulatory protein small-molecule disruptors. Nature 504, 437-440 (2013).

44. J. P. H. Wilding, M. Leonsson-Zachrisson, C. Wessman, E. Johnsson, Dose-ranging study with the glucokinase activator AZD1656 in patients with type 2 diabetes mellitus on metformin. Diabetes Obes. Metab. 15, 750-759 (2013).

45. K. Færch, D. Vistisen, G. Pacini, S. S. Torekov, N. B. Johansen, D. R. Witte, A. Jonsson, O. Pedersen, T. Hansen, T. Lauritzen, M. E. Jørgensen, B. Ahren, J. J. Holst, Insulin resistance is accompanied by increased fasting glucagon and delayed glucagon suppression in individuals with normal and impaired glucose regulation. Diabetes $\mathbf{6 5}$, 3473-3481 (2016).

46. A. Sharma, R. T. Varghese, M. Shah, C. D. Man, C. Cobelli, R. A. Rizza, K. R. Bailey, A. Vella, Impaired insulin action is associated with increased glucagon concentrations in nondiabetic humans. J. Clin. Endocrinol. Metab. 103, 314-319 (2018).

47. Y. Lee, E. D. Berglund, X. Yu, M.-Y. Wang, M. R. Evans, P. E. Scherer, W. L. Holland, M. J. Charron, M. G. Roth, R. H. Unger, Hyperglycemia in rodent models of type 2 diabetes requires insulin-resistant alpha cells. Proc. Natl. Acad. Sci. U.S.A. 111, 13217-13222 (2014).

48. M. G. Ismair, B. Stieger, V. Cattori, B. Hagenbuch, M. Fried, P. J. Meier, G. A. Kullak-Ublick, Hepatic uptake of cholecystokinin octapeptide by organic anion-transporting polypeptides OATP4 and OATP8 of rat and human liver. Gastroenterology 121, 1185-1190 (2001).

49. H. J. Gundersen, The smooth fractionator. J. Microsc. 207 (Pt. 3), 191-210 (2002).

50. P. O. Seglen, Preparation of isolated rat liver cells. Methods Cell Biol. 13, 29-83 (1976).

Acknowledgments: We thank R. Rizza and S. Inzucchi for reviewing the manuscript; the vTV Therapeutics LLC and Novo Nordisk GKA discovery teams for making the discovery of hepatoselective GKAs possible; and the patients, investigators, and site staff who participated in these studies. C. Wollheim (University Medical Center, Geneva, Switzerland) provided the rat pancreatic $\beta$ cells used in the in vitro characterization of TTP399. We also thank N. Cooper, E. Weselcouch, and D. Talag (PharmaWrite LLC, Princeton, NJ, USA) for medical writing and editorial assistance, which was funded by vTV Therapeutics LLC. This manuscript was prepared according to the ICMJE Uniform Requirements and the International Society for Medical Publication Professionals' Good Publication Practice for Communicating Company-Sponsored Medical Research: GPP3. Funding: This research was primarily funded by vTv Therapeutics LLC (High Point, NC, USA). Novo Nordisk A/S performed and funded some of the in vitro experiments and rodent pharmacology studies in support of this program. Medical writing and editorial assistance was funded by vTv Therapeutics LLC. Author contributions: A.V., I.D., J.B.B., and C.V. made substantial contributions to the conception or design of the work. All authors were involved in the acquisition, analysis, or interpretation of the clinical data. K.K. J.L.R.F., and C.V. were involved in the acquisition, analysis, or interpretation of the preclinical data for the work. All authors contributed to drafting the work or revising it critically for important intellectual content, gave final approval of the version to be published, and agreed to be accountable for all aspects of the work in ensuring that questions related to the accuracy or integrity of any part of the work are appropriately investigated and resolved. Competing interests: A.V. was a vTV Therapeutics LLC advisory board member in the past year and lead investigator of the AGATA trial. J.L.R.F., I.D., K.K., and C.V. are employees of vTV Therapeutics LLC. J.B.B. is a vTV Therapeutics LLC investigator and adviser under a contract through his employer. Data and materials availability: All data associated with this study are present in the paper or Supplementary Materials.

Submitted 2 March 2017

Resubmitted 7 June 2018

Accepted 10 December 2018

Published 16 January 2019

10.1126/scitranslmed.aau3441

Citation: A. Vella, J. L.R. Freeman, I. Dunn, K. Keller, J. B. Buse, C. Valcarce, Targeting hepatic glucokinase to treat diabetes with TTP399, a hepatoselective glucokinase activator. Sci. Transl. Med. 11, eaau3441 (2019). 